\title{
Immersion and Gameplay Experience: A Contingency Framework
}

\author{
Daniel Örtqvist ${ }^{1}$ and Mats Liljedahl ${ }^{2}$ \\ ${ }^{1}$ Department of Business Administration and Social Sciences (IES), Luleå University of Technology, 97187 Luleå, Sweden \\ ${ }^{2}$ Interactive Institute, Sonic Studio, Acusticum 4, 94128 Piteå, Sweden \\ Correspondence should be addressed to Mats Liljedahl, mats.liljedahl@tii.se
}

Received 16 February 2010; Revised 2 September 2010; Accepted 17 November 2010

Academic Editor: Michael Katchabaw

Copyright ( 2010 D. Örtqvist and M. Liljedahl. This is an open access article distributed under the Creative Commons Attribution License, which permits unrestricted use, distribution, and reproduction in any medium, provided the original work is properly cited.

\begin{abstract}
The nature of the relationship between immersion and gameplay experience is investigated, focusing primarily on the literature related to flow. In particular, this paper proposes that immersion and gameplay experience are conceptually different, but empirically positively related through mechanisms related to flow. Furthermore, this study examines gamers' characteristics to determine the influence between immersion and gameplay experiences. The study involves 48 observations in one game setting. Regression analyses including tests for moderation and simple slope analysis are used to reveal gamers' age, experience, and understanding of the game, which moderate the relationship between immersion and gameplay experience. The results suggest that immersion is more positive for gameplay experience when the gamer lacks experience and understanding of the game as well as when the gamer is relatively older. Implications and recommendations for future research are discussed at length in the paper.
\end{abstract}

\section{Introduction}

To date, gaming research has covered multiple disciplines including psychology and pedagogy as well as information and communication sciences, management and business, and different disciplines of engineering. Such broad interest has influenced the diversity of the research questions and the focus of the existing studies. One area that has recently drawn significant attention is the interactive nature of the game setting, focusing in particular on gamers' experiences and their consequences. As suggested by Ermi and Mäyrä, "The act of playing a game is where the rules embedded into the game's structure start operating, and its program code starts having an effect on cultural and social, as well as artistic and commercial realities. If we want to understand what a game is, we need to understand what happens in the act of playing, and we need to understand the player and the experience of gameplay" [1]. Following this statement, the current research specifically focuses on the nature of gameplay experiences.

One powerful gaming experience is immersion, which has been mentioned by gamers [2], designers [3], and game researchers [4] alike as an important experience of interaction. Research on gaming has examined the assumption of a strong relationship between immersion and gameplay experience, such that immersion is intertwined with gameplay experience-either by conceptual overlap or through a strong, positive, and linear relationship. Consequently, studies have been conducted on the antecedents of immersion in an attempt to more fully understand how to influence consumers of games (i.e., gamers) so that they experience both immersion and subsequent gameplay experience. Studies have found that immersion is related to the realism of the game world [5] as well as environmental and contextual sounds [6]. Immersion is also said to have depth [2]. Thus, the experience of immersion-which can be benefitted or harmed by game characteristics- has been deemed critical to game enjoyment. Yet little evidence supports such a strong relationship between immersion and gameplay experience. Indeed, only a few studies have truly investigated immersion's contribution (if any) to the gameplay experience. Therefore, the current study aims to investigate the nature of the relationship between immersion and gameplay experience as well as investigate contingencies influencing the relationship between immersion and gameplay experience.

In this paper, we discuss the ways in which the gameplay experience can be conceptualized, provide a model 
that organizes some of its fundamental components, and conclude with an assessment of the model, including some directions for further research. It should be noted that this study is exploratory in nature. As such, the goal is to generate new areas of discussion rather than propose results that are perfectly generalizable over different settings. The paper concludes with an analytical generalization in relation to results of previous studies in similar and different settings, offering proposals and guidance for future studies.

\section{Theory and Hypotheses}

Gameplay experience is one of the most central targets in the development of any game. The current study focuses on the temporal gameplay experience rather than players' weighted experience based on peer influence, game reviewers, or other social references. Gameplay experience is thus defined as "an ensemble made up of the player's sensations, thoughts, feelings, actions, and meaning making in a gameplay setting" [1]. As such, at the high end gameplay experience can be fun, challenging, and victorious. Our argument that follows is that gameplay experience is an attitude directed towards the game, which serves as a general opinion about the experience from the game.

A central component in understanding the gameplay experience is the influence of immersion [7]. Immersion has been studied both in the literature on games and also in the literature examining virtual reality. Studies focusing on virtual reality have, like studies on games, focused on contextually defining immersion, attempting to understand its antecedents and its relationship to enjoyment, and also to measure immersion. We have especially reviewed the literature on immersion related to games, and we do put forth some influential studies in Table 1. These studies have some common implications for our understanding of immersion and gameplay experience. First, while many studies have viewed immersion and gameplay experience as two very close conceptual constructs, we follow results from the literature review to argue that gameplay experience is a distinct construct from immersion. Gameplay experience relates to the gamer's development of attitudes toward the game whereas immersion is rather a synonym for presence when engaging in the game [8]. Similar studies reported in Table 1 have also viewed immersion (or presence) as generally separated from enjoyment (read gameplay experience). While separate, we do expect a strong, positive, and causal relationship between immersion and gameplay experience. The experience of being present in a game is generally perceived as a positive experience; hence, such an experience should result in the gamer developing positive attitudes for the game. As such, we believe that being immersed will lead to a certain gameplay experience.

Another general finding among the studies presented in Table 1 is that there are similarities between immersion and flow experiences. We here follow Csikszentmihalyi [1417] when conceptualizing flow as a holistic experience that people feel when they act with total involvement. We also believe that flow-like experiences could bridge the sense of being immersed to the positive evaluation leading to a sense
TABLE 1: Literature review of immersion.

\begin{tabular}{ll}
\hline Reference & Main results/implications \\
\hline Bnalyzed players' feelings towards \\
their favourite game and led them to \\
propose three gradual and successive \\
levels of player immersion: \\
engagement, engrossment, and total \\
immersion.
\end{tabular}

of gameplay experience. We return to this argument in the development of hypotheses in the study.

One central point of a conceptual separation of immersion and gameplay experience is the potential to allow their relationship to be dependent on contingent influences. According to a contingency framework, the gamer's characteristics moderate the relationship between immersion and gameplay experience such that immersion is expected to actually lead to different levels of gameplay experience. We draw from the literature related to flow to explain why a perceived presence in a game (i.e., immersion) can render different attitudinal developments (i.e., gameplay experience) depending on the characteristics of the person playing the game.

Gameplay experience is largely dependent on the perceptual interpretation of the gamer (labeled gamer characteristics) interacting with the immersion. Thus, we propose 


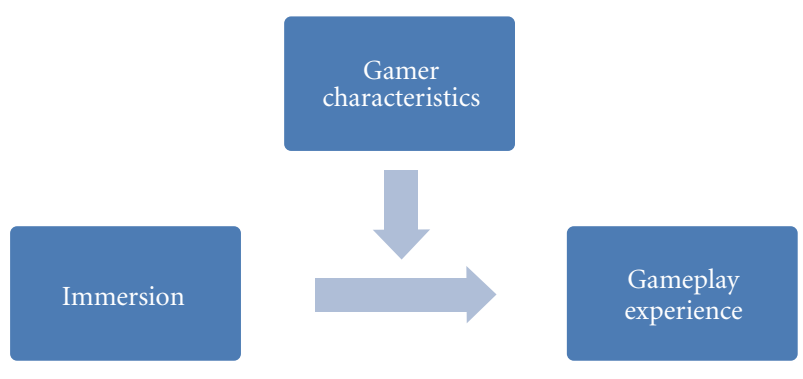

FIGURE 1: Research framework.

a model (see Figure 1) in which immersion is related to gameplay experience, but the magnitude of this influence is dependent on the characteristics of the gamer. This implies that immersion can evoke highly pleasant gameplay experiences for some gamers, but possibly even unattractive gameplay experiences for other gamers [18]. The following subsections introduce the rationale for a positive relationship between immersion and gameplay experience and discuss how gamers' age, experience, and game understanding influence the magnitude by which immersion influences gameplay experience.

2.1. Immersion and Gameplay Experience. Although the concept of immersion is frequently addressed by researchers and practitioners (i.e., players and game designers), the precision in the conceptual definition has been questioned [8]. Some have defined immersion as "the sensation of being surrounded by a completely other reality [... that takes over all of our attention, our whole perceptual apparatus" [19]. Immersion has also been defined as the "extent to which a person's cognitive and perceptual systems are tricked into believing they are somewhere other than their physical location" [20]. Overall, immersion refers to the success in a game to create an experience of escapism for the gamer. Following studies conducted on media, we refer to immersion as a psychological experience of nonmediation [21], which implies that significant immersion would relate to an experience of being in a world that is perceived to be generated by the computer instead of just using a computer [22].

Many studies treat immersion as a construct conceptually close to gameplay experience. We argue that these constructs are conceptually different, but empirically strongly related. Immersion is conceptually rooted in one's presence in the game while gameplay experience is an attitudinal evaluation of the experience of the game. Although the presence and the attitudinal evaluation are likely strongly related empirically, the conceptual foundation for immersion and gameplay experience is fundamentally different.

Researchers arguing that immersion is similar to presence often highlight that immersion is conceptually linked to Csikszentmihalyi's [14] conceptualization of flow. Following such trends, immersion has been labeled as "microflow" [18] and "gameflow" [23] to mention a few. The strong link between immersion and flow comes from the shared similarities in that both are interrupted when the task at hand is distracted; consequently, both require attention, alter one's sense of time, and lead to the sense of self being lost [8]. The conceptual arguments related to flow were developed to account for the pleasure found by immersion in everyday activities [15-17]. Although not explicitly developed to explain gameplay experience, conceptualizations of flow resonate well with reports of causes of gameplay experience and can explain how immersion and gameplay experience are different as well as why immersion is linked to rewarding gameplay experiences.

In essence, we suggest that the mechanism that transfers immersion to gameplay experience is based on flow. The flow-like experience of immersion triggers a powerful sense of gratification that is manifested in a rewarding gameplay experience (i.e., an experience that creates an attitude). In accordance with Csikszentmihalyi [17], the escape from the real world through fantasy behavior creates arousing and relaxing sensations, which in turn influence the attitudinal evaluation of the gameplay experience. As such, we propose the following hypothesis.

Hypothesis 1. Immersion is (a) conceptually different from but (b) positively related to gameplay experience.

2.2. Age. The first situational contingency is related to the gamer's age. Immersion is generally positively related to the gameplay experience, yet the level of gameplay experience developed from a certain level of immersion is dependent on the gamer's age. We argue in our theorizing that older gamers will experience more rewarding gameplay experiences from increases in immersion than younger gamers.

Much research has shown that a difference exists in the appraisal of rewards depending on age. In media work, Rettie [24] found that younger respondents did not experience the same rewards when engaging in activities on the Internet, where they were exposed to challenges perceived as stressful and irritating instead of evaluating the immersion as a rewarding state. Similar arguments have been posted in studies examining flow. For instance, Csikszentmihalyi [25] argued that with age immersion-like experiences become increasingly rare; therefore, each experience of immersion adds to the development of positive attitudes (i.e., gameplay experience in this case). Thus, we suggest that age has a moderating influence on the relationship between immersion and gameplay experience.

Hypothesis 2. Age moderates the relationship between immersion and gameplay experience such that increases in immersion more positively influence the gameplay experience for gamers who are older compared to gamers who are younger.

2.3. Experience. The second situational contingency is related to the gamer's experience of gaming. In specific, we suggest that the level of gameplay experience developed from a certain level of immersion will be dependent on the gamer's experience of gaming. We argue in our theorizing that gamers with low gaming experience will experience 
more rewarding gameplay experiences from increases in immersion than gamers with high gaming experience.

Gamers with higher gaming experience will not experience the same reward effects from yet another flow-like experience; rather, they are more used to the transitions between the real and the created reality [25]. As such, the emotional influence triggering the attitudinal evaluation of the gaming experience would likely be deemed as less rewarding for a more experienced gamer compared to a novice gamer. Indeed, Novak et al. [26] examined online experiences and found that "the degree to which the online experience is compelling appears to decrease with years of experience online." As such, it is possible to assume thatalthough experiencing a presence-gamers with significant experience would consider the fact that they were facing challenges below their skill threshold when evaluating and forming their attitudes of gameplay experience. Hence, we propose that experience moderates the influence of immersion on gameplay experience.

Hypothesis 3. Gaming experience moderates the relationship between immersion and gameplay experience such that increases in immersion more positively influence the gameplay experience for gamers with low gaming experience compared to gamers with high gaming experience.

2.4. Game Understanding. The third situational contingency is related to the gamer's understanding of the game, suggesting that the level of gameplay experience developed from a certain level of immersion will be dependent on the gamer's understanding of the game. We argue that gamers with a limited understanding of the game will experience more rewarding gameplay experiences from increases in immersion compared to gamers with a higher level of understanding of the game.

Gamers with a comparably lower understanding of the game, but who still feel a presence in the game (i.e., immersion), will likely use their senses to a greater degree to fill in information when they do not understand the situation. This type of presence would likely positively influence the attitudinal evaluation of the gameplay experience, as it requires the gamer to be alert and emotionally intertwined with the game to a greater extent than a gamer who does not need to understand or learn in order to complete the game. Thus, it is more likely that a person who does not extensively use all the senses relies on less concentration, which has been proven to interrupt flow-like situations and lead to a more negative evaluation of the experience [27]. In addition, experienced challenges are positively related to flow-like experiences, transforming into rewarding attitudinal evaluations (see, for instance, Kim et al. [28]), such as evaluations of gameplay experience. Based on this argument, we propose that game understanding moderates the relationship between immersion and gameplay experience.

Hypothesis 4. Game understanding moderates the relationship between immersion and gameplay experience such that increases in immersion more positively influence the gameplay experience for gamers with less game understanding than gamers with more game understanding.

\section{Research Methods}

The present study employed an experimental approach to test the nature of the relationship between immersion and gameplay experience and to investigate contingencies to this relationship. We used a single game setting-Beowulfas our experimental vehicle (see next sub-section for an introduction to Beowulf). One advantage of sampling from a single game setting compared to multiple settings is reduced external variance, as universal factors are deemed to be more prominent in isolation. All gamers experienced the same game and played for the same length of time, thereby reducing alternative explanations for findings. Also, our selected game was audio based and developed for short gaming sessions. The plot and layout of the game was simple enough for the surveyed gamers to quickly get started with the game. These features of the game provided advantages given that we needed to do the study with individuals who played the game for only a short while. While the game setting has its unique characteristics, it still has common features for how to relate to the game (even if this is driven more by sound compared to graphics). We believe the game to be representative in how immersion and gameplay experience relate and are influenced by gamers' characteristics. The following subsections describe the research setting (i.e., the game), the sample and data collection, and the technique for measuring the phenomena under study.

3.1. Research Setting. Beowulf [29] is a heroic epic poem that experts believe was written sometime between 700 and 1000 A.D. It is sometimes referred to as England's national epic. In the Beowulf game used in the current study, one small episode of the long poem is lifted out and translated into a gameplay scenario. The episode in the poem narrates how the Scandinavian hero Beowulf defeats the monster Grendel in its lair.

In the game, Grendel lurks in a dark system of caves and tunnels inhabited not only by the monster itself, but also by wolverines, snakes, bats, and a host of potential dangers. As our hero enters the first cave, a gust of wind blows out his torch and darkness descends. The player, as Beowulf, must now completely trust in his/her hearing to navigate a route to the monster, with only minimal help from a simple revealing map. The task is to successfully navigate the hazards lying between the cave entrance and the monster. The player interprets the myriad of sounds that fill the environment both for navigation and for confrontational combat situations. Finally, the monster must be located and dispatched with a well-timed swing of Beowulf's sword.

A majority of the output stimuli from the game are sounds; indeed, gameplay is driven almost entirely by audio, with only sparse and coarse-grained visuals. This approach is called an "audio mostly game." An audio mostly game is not a game for visually impaired persons; rather, it is a game for hearing, possibly sighted persons who have various reasons for requesting the shift from eye to ear. In this sense, the 
Beowulf project is different from the numerous audio-only game projects for persons who are visually impaired.

A nondetailed map represents the game world graphically. This map shows only the parts of the cave system that the player has visited so far. The map slowly reveals the game world as the player progresses through and explores it. Figure 2 shows one example of what this revealing map can look like after a couple of minutes of play.

Navigating and moving in the game world are controlled using the arrow keys on the computer keyboard in the same way as in the Sleuth game [30]. The blue triangular arrow in Figure 2 shows both the players' current position and current direction: north, south, east, or west. The right arrow key turns the current direction 90 degrees clockwise; the left arrow key turns the current direction 90 degrees anticlockwise. If the current direction is "east," as in Figure 2, pressing the right arrow key will alter the current direction to "south" while pressing the left arrow key will alter the current direction to "north." The up arrow key moves the current position one "map point" step in the current direction. In the situation illustrated by Figure 2, pressing the up arrow key will move the player one step east (right). If the player tries to move to a map point that does not exist, the blue arrow is not advanced, and a "bump" sound is played, indicating that the player hit a wall.

Having reduced the visual support to merely a simple revealing map, the soundscape perceptually takes several steps forward and becomes crucial in moving around the game world and handling the challenges and situations encountered. The soundscape is three dimensional. Players localize items and find directions by listening, moving, and turning, using the same stereophonic principles as in real life. Headphones ensure that players experience the necessary stereo sound experience.

Beowulf is a first-person listener game in which the player hears through Beowulf's ears. Very little visual information is provided to guide the player's perception. Instead Beowulf's soundscape takes over most of the responsibility for communicating the properties of the game world, traditionally done through graphics. For this to work, all sounds have to be very realistic, of high quality, and carefully implemented.

3.2. Sample and Data Collection Procedures. Data were collected from a quota sample consisting of 48 individuals in an experimental setting. Four settings were used to collect data in order to ensure that sufficient variance existed in the data; thus, the data collection design was similar to a stratified sample. Each of the four groups comprised 12 respondents. Group 1 was made up of music conservatory students who were 20 to 25 years old. Group 2 was high school students from southwest Sweden who were 13 to 15 years old. Group 3 was art and design students who were 20 to 25 years old. Group 4 was high school students from northeast Sweden who were 13 to 15 years old. This type and size of sample is quite common in similar studies examining immersion. Similar studies have even addressed similar research questions with similar analytic methods using 25 respondents [9].

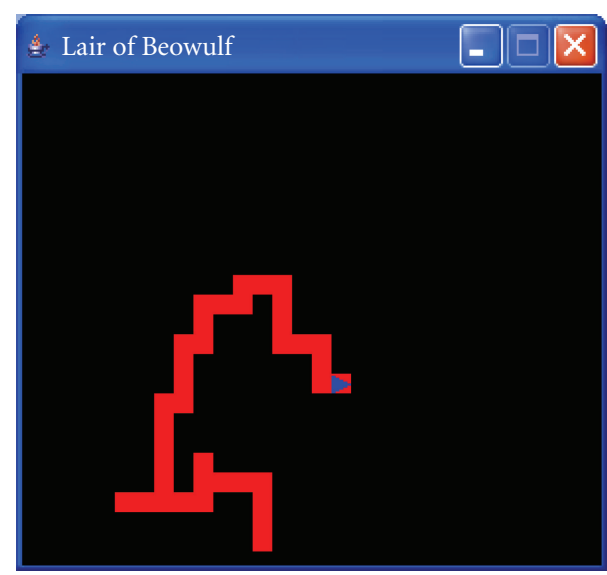

FIGURE 2: The revealing map.

Data were collected in an experiment setting in which respondents were asked to first try out the game and then give immediate feedback. As accuracy in filling out questionnaires decreases with time, we found it important that the respondents be able to discuss flow in an environment both physically and temporally close to their experience. During the test, the subjects first got a short introduction to the game, its background, and the Beowulf story as well as instructions on how to navigate in the game using the arrow keys on the computer keyboard. The test situation was conducted on identical laptops (Apple MacBook Pro), with all subjects using Koss Portapro headphones to ensure consistent audio parameters.

After having played the game for approximately ten minutes, the subjects started to fill out the questionnaire (described in Section 3.3). The test session was ended once the questionnaire was completed. Each session lasted approximately 30 minutes and was supervised by one of the authors.

3.3. Measurement. A questionnaire was developed and administered to the sample in the gaming setting. The respondents were asked to complete the questionnaire after they had played the game for about ten minutes. The questionnaire contained in total 24 questions using a 7-point Likert scale with the same anchors ( 1 = strongly disagree, and 7 = strongly agree) and 6 open-ended questions in which the respondents could provide more qualitative data on the experiences with the game.

3.3.1. Gameplay Experience. Gameplay experience was measured using three items on a seven-point Likert scale. The items were related to experiences of the game, including the gamers' attitude to the time it took to experience the game as interesting, the number of challenges in the game, and the amount of time needed to complete the game. A typical item was worded "It took very long time to play the game" (reversed scored). Gamers who expressed that they quickly became emotionally engaged in the game, that they were interested in more challenges, and that the game ended too fast were interpreted as exhibiting a high gameplay 
experience. The average gameplay experience was 5.24, with a standard deviation of 1.20 .

3.3.2. Immersion. Immersion was measured as a composite construct from two items, both assessed on a seven-point Likert scale. The items were related to the gamers' sense of being completely engaged in the game as well as how easy it was to grasp their presence in the gaming world. A typical item was worded: "I was completely engaged in the game". The average immersion in the sample was 5.24, with a standard deviation of 1.18 .

3.3.3. Age. The study was conducted on a sample with two age categories: younger gamers (i.e., gamers between 12 and 18 years of age) and slightly older gamers (i.e., between 19 and 25 years of age). Due to the within-group homogeneity of the responses, age was categorized as a dichotomous variable in which the younger group was coded as 1 and the older groups as 2 . Half (50\%) of the sample were younger gamers.

3.3.4. Gaming Experience. Gaming experience was comprised of a single item assessed on a seven-point Likert scale. Gamers were asked to respond to a statement about how frequently they play games (i.e., "I often play computer games"), which was used as a proxy for gaming experience. The average response was 4.33 , with a standard deviation of 2.06 .

3.3.5. Game Understanding. Game understanding was measured using four items assessed on a seven-point Likert scale. The items related to the gamers' experience-namely, they found it easy to know when to use items embedded in the game, easy to understand what to do in the game, easy to understand when things happened, and easy to know how to act when things happened. A typical item was worded: "I immediately understood when I was under attack in the game". The average response was 4.46 , with a standard deviation of 1.42 .

3.4. Methods for Analyses. Hypotheses were tested by employing regression analyses following recommendations for evaluation of moderation. To retain statistical power due to the number of observations, the hypotheses were tested in isolation.

\section{Results}

First, we evaluated the psychometric properties of the variables adopted to test the hypotheses. Table 2 presents the descriptive statistics and the correlations of the variables in the study. We found initial support for our hypothesis as the measure of immersion was positively related to gameplay experience. The threat of multicollinearity is low: the highest correlation coefficient is about .39. To reduce multicollinearity among the independent variables and the interaction terms, the variables used to compute interaction terms were standardized. Reliability estimates (i.e., Cronbach's alpha)
TABle 2: Descriptive Statistics.

\begin{tabular}{|c|c|c|c|c|c|c|c|c|c|}
\hline & Min & Max & Ave & St.D. & 1 & 2 & 3 & 4 & 5 \\
\hline $\begin{array}{l}\text { (1) Gameplay } \\
\text { experience }\end{array}$ & 1.67 & 7.00 & 5.24 & 1.20 & 1.00 & & & & \\
\hline (2) Immersion & 2.00 & 7.00 & 5.24 & 1.18 & $.35^{*}$ & 1.00 & & & \\
\hline (3) Age & 1.00 & 2.00 & 1.52 & 0.50 & .24 & .27 & 1.00 & & \\
\hline (4) Experience & 1.00 & 7.00 & 4.33 & 2.06 & .22 & .08 & .07 & 1.00 & \\
\hline $\begin{array}{l}\text { (5) Game } \\
\text { understanding }\end{array}$ & 1.50 & 7.00 & 4.46 & 1.42 & $.38^{* *}$ & $.39^{* *}$ & .17 & .07 & 1.00 \\
\hline
\end{tabular}

were acceptable (i.e., $\alpha>$.70) in relation to recommended levels (Nunnally [31]; Fornell and Larcker [32]).

After establishing initial support (i.e., by correlational analyses) for hypothesized relationships and support for the psychometric properties of the studied variables, we continued by examination of the hypotheses. First, we tested the argument that immersion and gameplay experience are two distinct constructs which are positively related. Second, we tested the moderation by gamers' characteristics (i.e., age, experience, and game understanding). In order to retain statistical power due to the sample size we tested the moderating influences in separate models. We followed general guidelines for how to test categorical and continuous moderation effects (Aiken and West [33]; Baron and Kenny [34]).

4.1. Immersion and Gameplay Experience. We argued in the first hypothesis that immersion is (a) conceptually different from and (b) positively related to gameplay experience. To test the first part of the hypothesis we performed a simultaneous principal component analysis with Oblimin Kaiser normalization of the items (i.e., variables) measuring immersion and gameplay experience. If the factor analysis extracts two factors with eigenvalues above one, and where loadings of items are according to measurement, then the first part of the hypothesis is supported. Secondly, to test whether immersion and gameplay experience are positively related, we performed a simple regression analysis where immersion is the independent variable and with gameplay experience is the dependent variable.

A principal component analysis with Oblimin Kaiser normalization (four rotations) revealed two distinct factors with eigenvalues over one (see Table 3 ). The first factorimmersion-contained two items which both related to the immersion factor with loadings between .77 and .85, and with simultaneous low loadings to the gameplay experience factor (i.e., loadings below .10). Similarly, the three items measuring gameplay experience revealed loadings between .67 and .85 on gameplay experience, and simultaneous loadings below .15 on the immersion factor. This supports the first part of the hypothesis, that immersion is conceptually different from gameplay experience.

The second part of the hypothesis concerned the influence by immersion on gameplay experience. Regression analysis reveals that immersion explains $10 \%$ of the variance in gameplay experience according to the adjusted $R$ 
Table 3: Principal component analysis.

\begin{tabular}{|c|c|c|c|}
\hline \multirow{2}{*}{ Factors } & \multirow{2}{*}{ Variables } & \multicolumn{2}{|l|}{ Factor } \\
\hline & & Gameplay experience & Immersion \\
\hline \multirow{2}{*}{ Immersion } & Variable 1 &, 070 & ,766 \\
\hline & Variable 2 &,- 057 &, 848 \\
\hline \multirow{3}{*}{$\begin{array}{l}\text { Gameplay } \\
\text { experience }\end{array}$} & Variable 3 &, 727 &,- 091 \\
\hline & Variable 4 & 674 &, 149 \\
\hline & Variable 5 &, 850 &,- 008 \\
\hline
\end{tabular}

TABLE 4: Regression results.

\begin{tabular}{lccccc}
\hline & \multicolumn{2}{l}{$\begin{array}{l}\text { Unstandardized } \\
\text { coefficients }\end{array}$} & $\begin{array}{c}\text { Standardized } \\
\text { coefficients }\end{array}$ & $T$ & Sig. \\
& $B$ & $\begin{array}{c}\text { Std. } \\
\text { Error }\end{array}$ & Beta & $B$ & $\begin{array}{c}\text { Std. } \\
\text { Error }\end{array}$ \\
\hline (Constant) & 5,236 &, 164 & & 31,984 &, 000 \\
Immersion &, 412 &, 165 &, 345 & 2,491 &, 016 \\
\hline
\end{tabular}

${ }^{\mathrm{a}}$ Dependent variable: gameplay experience.

square value. Further, the regression model is significant $\left(F=6,21^{*}\right)$, and immersion is a significant predictor of gameplay experience with a standardized coefficient of .35 (see Table 4). This supports the second part of the hypothesis that immersion is positively related to gameplay experience. Overall, we found support for hypothesis one, and thereby we found support for a chain reaction which sets of in the flow-like experience of being immersed, which in turn will render positive attitudes, and finally be positively related to gameplay experience. As we found support for our central hypothesis, we continue by examining if this influence is dependent upon characteristics of the gamer.

4.2. Age. We next examine the role of the gamers' age as a moderating variable on the relationship between immersion and gameplay experience. We found the model including the interaction term to explain $17 \%$ of the variance in gameplay experience, which should be compared to the $10 \%$ explained by immersion only. The regression model is significant $\left(F=4.19^{*}\right)$ and the interaction term (immersion $\times$ age) is significant (see Table 5), which implies that the relationship between immersion and gameplay experience is dependent on the gamers' age, in accordance with the second hypothesis. As such this test strongly supported hypothesis two as the inclusion of the interaction term explained substantially more variance in the dependent variable and since the interaction term was significant. We continue by examining the support for hypothesis two by examining the nature of the interaction effect. First we plot the interaction effect, and thereafter we perform simple slope analyses.

Figure 3 plots the relationship between immersion and gameplay experience at the two age groups studied. We have followed guidelines for plotting moderation effects including categorical variables. As obvious from the plot, both slopes are positive but the slope for the older group is steeper suggesting that immersion is more important for the older group, and that the younger group still rates the gameplay
TABLE 5: Regression results.

\begin{tabular}{lccccc}
\hline Coefficients & \multicolumn{2}{l}{ Unstandardized } \\
& coefficients & $\begin{array}{c}\text { Standardized } \\
\text { coefficients }\end{array}$ & $T$ & Sig. \\
& $B$ & $\begin{array}{c}\text { Std. } \\
\text { Error }\end{array}$ & Beta & $B$ & $\begin{array}{c}\text { Std. } \\
\text { Error }\end{array}$ \\
\hline (Constant) & 5,335 &, 164 & & 32,505 &, 000 \\
Immersion &, 482 &, 175 &, 403 & 2,756 &, 008 \\
Age &, 155 &, 166 &, 130 &, 933 &, 356 \\
Immersion $\times$ &,- 377 &, 179 &,- 297 & $-2,103$ &, 041 \\
Age & & & & & \\
\hline
\end{tabular}

${ }^{\mathrm{a}}$ Dependent variable: gameplay experience.

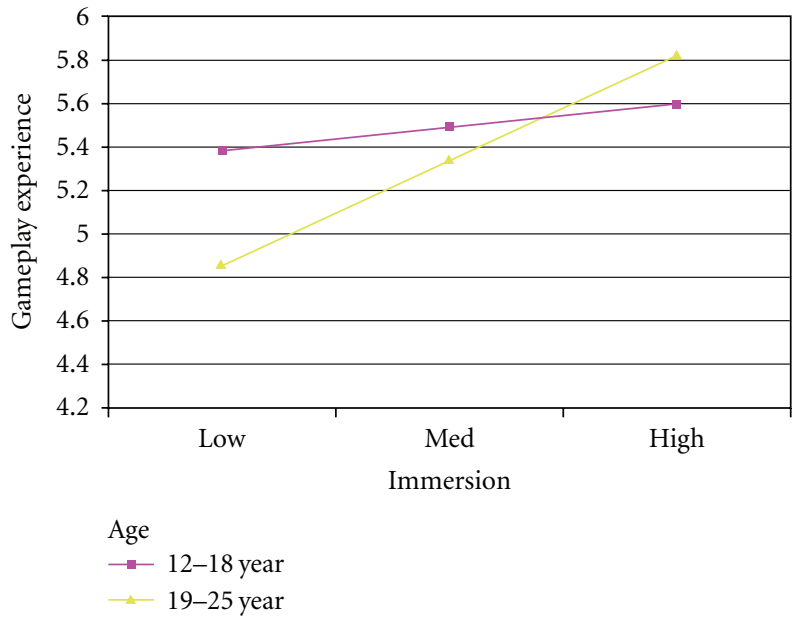

FIGURE 3: Interaction between immersion and age on gameplay experience.

TABLE 6: Simple slope analysis.

\begin{tabular}{lcc}
\hline & \multicolumn{2}{c}{ Categorical moderator } \\
& $12-18$ years & $19-25$ years \\
\hline Simple slope & 0,105 & 0,482 \\
Standard error & 0,207 & 0,176 \\
$T$-value & 0,506 & 2,738 \\
Significance & 0,615 & 0,009 \\
Degrees of freedom & & 44 \\
\hline
\end{tabular}

experience higher (compared to the older group) when immersion is low.

Further analysis of these slopes (as can be viewed in Table 6) shows that the slopes are differently positive (.11 for the younger group and .48 for the older group). However, only the older group is significant $(T$-value $>1.96 ; P<$ $.05)$. Therefore, it is not possible to state that immersion has any influence whatsoever for the gameplay experience of the younger group, while we provide evidence for the importance of immersion for the older group. Hence, the results are in line with our arguments that with age the flowlike experience of immersion adds more to the development of positive attitudes (i.e., gameplay experience in this case). As such we find support for hypothesis two. 
TABLE 7: Regression results.

\begin{tabular}{|c|c|c|c|c|c|}
\hline & \multicolumn{2}{|c|}{$\begin{array}{l}\text { Unstandardized } \\
\text { coefficients }\end{array}$} & \multirow{2}{*}{$\begin{array}{c}\text { Standardized } \\
\text { coefficients } \\
\text { Beta }\end{array}$} & \multirow{2}{*}{$\begin{array}{l}T \\
B\end{array}$} & \multirow{2}{*}{$\begin{array}{l}\text { Sig. } \\
\text { Std. } \\
\text { Error }\end{array}$} \\
\hline & $B$ & $\begin{array}{l}\text { Std. } \\
\text { Error }\end{array}$ & & & \\
\hline (Constant) & 5,257 &, 159 & & 33,061 &, 000 \\
\hline Immersion & ,332 & , 165 & ,277 & 2,012 & ,050 \\
\hline $\begin{array}{l}\text { Gaming } \\
\text { experience }\end{array}$ & ,235 &, 161 & ,197 & 1,465 & ,150 \\
\hline $\begin{array}{l}\text { Immersion } \times \\
\text { Gaming } \\
\text { experience }\end{array}$ &,- 288 & , 167 &,- 237 & $-1,726$ & ,091 \\
\hline
\end{tabular}

${ }^{\mathrm{a}}$ Dependent variable: gameplay experience.

4.3. Experience. We next examine the role of gaming experience as a moderating variable on the relationship between immersion and gameplay experience. The theoretical logic underpinning this argument is that increases in immersion more positively influence the gameplay experience for gamers with low gaming experience compared to gamers with high gaming experience. As such, we expect gamers with low gaming experience to have the most positive effect (i.e., the highest slope) of immersion on gameplay experience. We found the model, including the interaction term, to explain $16 \%$ of the variance in gameplay experience, which should be compared to the $10 \%$ explained by immersion only. The regression model is significant $\left(F=3.89^{*}\right)$, but the interaction term is marginally significant (i.e., $P<.10$ ). As such, we find but partial support for the moderating relationship of gaming experience on immersion-gameplay experience relationship (see Table 7 for more details on the results). Since the interaction term is at least marginally significant, we continue by examining the support for hypothesis three by examining the nature of the interaction effect. First we plot the interaction effect, and thereafter we perform simple slope analyses.

Figure 4 plots the relationship between immersion and gameplay experience at three levels of gamers' experience, low corresponds to one standard deviation below average, med stands for average, and high is one standard deviation above average. We have followed guidelines for plotting moderation effects including continuous variables. As obvious from the plot, all three slopes are positive, but the slope for gamers with lower experience is more steep compared to the other slopes. In fact, the slope for the experienced gamers seems almost to indicate no relationship between immersion and gameplay experience.

Further analyses (as can be viewed in Table 8) reveal all three slopes to be positive. However, only the simple slope for the gamers with low experience is significant ( $T$-value $>1.96$; $P<.05)$. Therefore, it is not possible to state that immersion has any influence whatsoever for the gameplay experience of the gamers with average or high experience, while we provide evidence for the importance of immersion for the group with low experience. Hence, we find partial support for hypothesis three as the interaction term was marginally significant and the slopes behaved as predicted in the hypothesis.

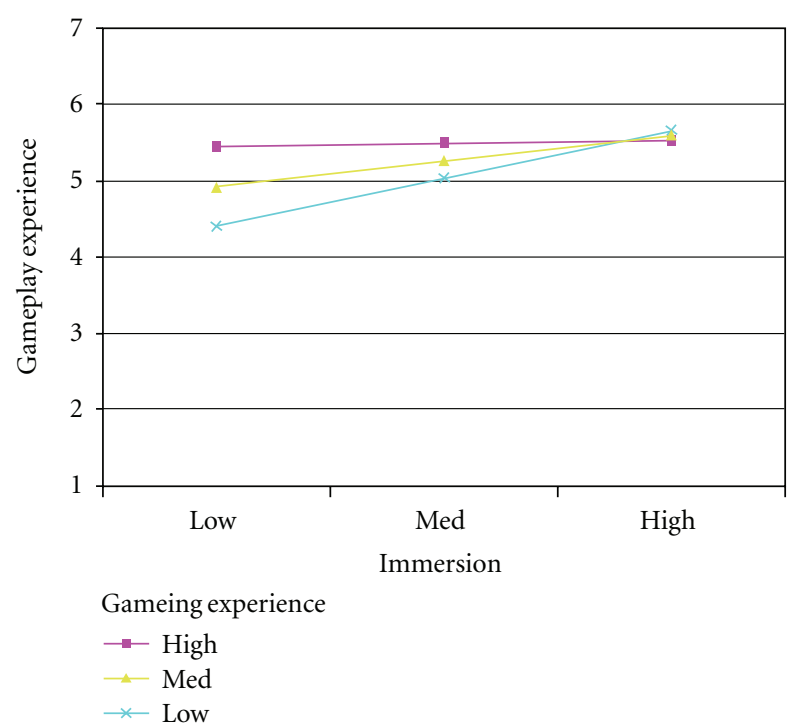

FIGURE 4: Interaction between immersion and gaming experience on gameplay experience.

TABLE 8: Simple slope analysis.

\begin{tabular}{lccc}
\hline & \multicolumn{3}{c}{ Continuous Moderator } \\
& Low & Med & High \\
\hline Simple slope & 0.620 & 0.332 & 0.044 \\
Standard error & 0.207 & 0.213 & 0.259 \\
$T$-value & 3.000 & 1.562 & 0.170 \\
Significance & 0.005 & 0.126 & 0.866 \\
Degrees of freedom & & 44 & \\
\hline
\end{tabular}

4.4. Game Understanding. We next examine the role of the gamers' understanding for the game as a moderating variable on the relationship between immersion and gameplay experience. We found the model including the interaction term to explain $23 \%$ of the variance in gameplay experience, which should be compared to the $10 \%$ explained by immersion only. The regression model is significant $\left(F=5.76^{* *}\right)$ and the interaction term is significant, which implies that the relationship between immersion and gameplay experience is dependent on gamers' understanding for the game, in accordance with the fourth hypothesis. As such, this test strongly supported hypothesis four as the inclusion of the interaction term (immersion $\times$ game understanding) explained substantially more variance in the dependent variable and since the interaction term was significant (see Table 9 for full details). We continue by examining the support for hypothesis four by examining the nature of the interaction effect. First, we plot the interaction effect, and thereafter we perform simple slope analyses.

Figure 5 plots the relationship between immersion and gameplay experience at three levels of game understanding, low corresponds to one standard deviation below average, med stands for average, and high is one standard deviation above average. We have followed guidelines for plotting moderation effects including continuous variables. As obvious 
TABLE 9: Regression results.

\begin{tabular}{lccccc}
\hline & \multicolumn{2}{l}{$\begin{array}{l}\text { Unstandardized } \\
\text { coefficients }\end{array}$} & $\begin{array}{c}\text { Standardized } \\
\text { coefficients }\end{array}$ & $T$ & Sig. \\
& $B$ & $\begin{array}{c}\text { Std. } \\
\text { Error }\end{array}$ & Beta & $B$ & $\begin{array}{c}\text { Std. } \\
\text { Error }\end{array}$ \\
\hline $\begin{array}{lcccc}\text { Constant }) \\
\text { Immersion }\end{array}$ & 5,356 &, 159 & & 33,605 &, 000 \\
$\begin{array}{l}\text { Game } \\
\text { understanding }\end{array}$ &, 251 &, 171 &, 210 & 1,474 &, 148 \\
$\begin{array}{l}\text { Immersion } \times \\
\begin{array}{l}\text { Game } \\
\text { understanding }\end{array}\end{array}$ &,- 315 &, 133 &,- 318 & $-2,367$ &, 022 \\
\hline
\end{tabular}

${ }^{a}$ Dependent variable: gameplay experience.

TABLE 10: Simple slope analysis.

\begin{tabular}{lccc}
\hline & \multicolumn{3}{c}{ Continuous moderator } \\
& Low & Med & High \\
\hline Simple slope & 0,710 & 0,395 & 0,080 \\
Standard error & 0,249 & 0,171 & 0,184 \\
$T$-value & 2,851 & 2,314 & 0,434 \\
Significance & 0,007 & 0,025 & 0,667 \\
Degrees of freedom & & 44 & \\
\hline
\end{tabular}

from the plot, all three slopes are positive, but the slope for the gamers with low game understanding is more steep compared to the other slopes. In fact, the slope for gamers' experiencing a high game understanding seems almost to indicate no relationship between immersion and gameplay experience.

Further analyses (as can be viewed in Table 10) reveal all three slopes to be positive. However, the simple slope for gamers with low and average game understanding is positive and significant $(T$-value $>1.96 ; P<.05)$. Therefore, it is not possible to state that immersion has any influence for the gameplay experience of gamers' with high understanding for the game, while we provide evidence for the importance of immersion for the group with low and average game understanding. Hence, we find support for hypothesis four as the interaction term was significant, and the slopes behaved as predicted in the hypothesis.

\section{Discussion and Conclusions}

The aim of this study was to examine the relationship between immersion and gameplay experience. Specifically, this study conceptually differentiated between immersion and gameplay experience and examined contingencies influencing the magnitude of influence between immersion and gameplay experience. We found support for our arguments based upon arguments related to flow; moreover, we determined that immersion is a separate, although empirically related construct to gameplay experience. Finally, several individual characteristics influenced the magnitude by which immersion influences gameplay experience.

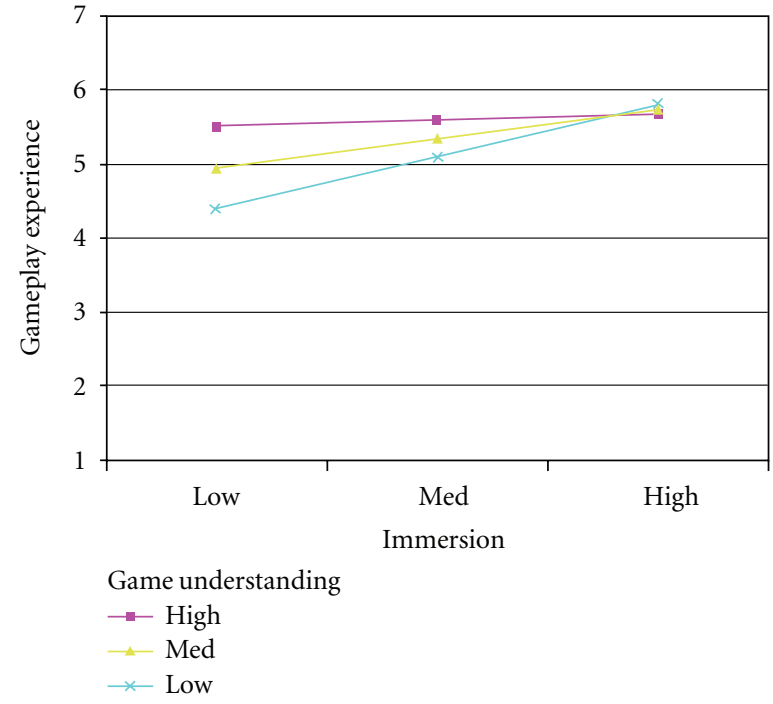

FIGURE 5: Interaction between immersion and game understanding on gameplay experience.

Specifically, this study supports the claim that immersion can create a flow-like sense which in turn fosters a positive attitude (i.e., gaming experience) towards the gaming situation. We also established that the characteristics of the gamer can influence how likely it is that flow-like states are actually achieved. As such, we proposed and found support for the moderating role of age: older individuals experienced more impact on gameplay experience from immersion. This study also found marginally significant support for the moderating role of experience, implying that individuals with limited gaming experience perceived larger effects from immersion on gameplay experience. This study also found support for the moderating role of game understanding, such that individuals with less game understanding experienced larger effects from immersion upon gameplay experience. Interestingly, in some of the settings, it seemed that immersion did not influence gameplay experience at all.

The separation of immersion and gameplay experience in modeling, together with tests of moderation effects, makes possible a deeper understanding of the role and impact of creating immersion in games. In fact, the effect of immersion is not always positively and strongly related to gameplay experience. To a large extent, it depends on gamers' characteristics (i.e., age, experience, and understanding). This implies that game development is much more complex than merely creating senses of escapism for the gamer; rather, it is about combining the game plot with the characteristics of the intended segment of gamers.

Further, the present study holds implications for research on human-computer interaction as it highlights that gaming follows what has been labeled "the pleasure principle" [10]. That is, individuals who become immersed in their interaction with the game will experience affective pleasures and hence evaluate the game experience positively. The conceptualizations and empirical tests also strengthens recent developments in gaming literature that supports that flow can be 
used to understand the affective reactions of gamers, and that immersion is a core central experience for developing these affective reactions [9]. Further, by following developments in flow literature we also learn that the characteristics of the gamer influence the magnitude by which immersion actually triggers flow-like states that influence and develop affective pleasures and thereby gameplay experience.

As with any study, limitations do exist. The sample in the current study was rather limited and specific, meaning it may be difficult to generalize the results to other contexts. However, analytical arguments do not suggest that this sample is specific in any way; thus, further testing of these results in other samples should be conducted in order to generalize findings. Another potential limitation is related to the very specific game setting studied. While choosing a specific game setting has several advantageous (as it for instance reduces external variance and noise) it could also provide differences which make the results difficult to generalize for other games. Although our current belief is that the results from this study have potential to transfer to similar settings, as they are based on sound conceptual arguments and relate well to previous literature, they should still be replicated to examine the full potential of generalizability from the study. In addition, although the study design had several advantages, it actually proposed a limitation in terms of the potential to test causality. Although it is likely that immersion influences gameplay experience rather than the opposite, future studies should test a cross-lagged design to examine whether the relationship between immersion and gameplay experience takes the nature of regular, reversed, or reciprocal causation.

We also acknowledge that other factors could be relevant to include in a study on gameplay experience besides those used in this study. Our goal was to produce a very restricted set of insights to clarify points from the wellknown and established literature. As such, we only needed constructs that captured immersion, gamers' characteristics, and gameplay experience. Of course, other constructs related to gamers' characteristics should be examined in future research, as those adopted here are only examples.

Despite the limitations, we believe the merit of this study is that it makes a number of contributions to the emerging literature on gameplay experience. Specifically, it clarifies the distinction and relation between immersion and gameplay experience, which most studies seem to have neglected. We also use several analytical techniques to evaluate the robustness of our findings.

\section{References}

[1] L. Ermi and F. Mayra, "Changing views: worlds in play," in Proceedings of the 2nd International Conference on Digital Games Research Association (DiGRA '05), S. de Castell and J. Jenson, Eds., pp. 15-27, Vancouver, Canada, June 2005.

[2] T. Chown, "Review: Championship Manager 00/01," 2000, http://www.gamesdomain.co.uk/gdreview/zones/reviews/pc/ nov00/cm001.html.

[3] E. Swing, "Adding immersion to collaborative tools," in Proceedings of the 5th Symposium on the Virtual Reality Modeling Language (VRML '00), pp. 63-68, February 2000.
[4] A. Radford, "Games and learning about form in architecture," Automation in Construction, vol. 9, no. 4, pp. 379-385, 2000.

[5] F. Housten, "Review: Thief: The Dark Project," 1998, http:// gamesdomain.com/gdreview/zones/pc/dec98/thief.html.

[6] D. Benge, "Review: Sanatorium," http://www.gamesdomain .co.uk/gdreview/zones/reviews/pc/jun98/sanity.html.

[7] L. Nacke and C. A. Lindley, "Flow and immersion in firstperson shooters: measuring the player's gameplay experience," in Proceedings of the Conference on Future Play: Research, Play, Share, pp. 81-88, Toronto, Canada, 2008.

[8] E. Brown and P. Cairns, "A grounded investigation of game immersion," in Extended Abstracts on Human Factors and Computing Systems (CHI '04), pp. 1297-1300, ACM Press, Vienna, Austria, April 2004.

[9] L. Nacke and C. A. Lindley, "Flow and immersion in firstperson shooters: measuring the player's gameplay experience," in Proceedings of the Conference on Future Play: Research, Play, Share, Future Play, pp. 81-88, November 2008.

[10] Y. Douglas and A. Hargadon, "The pleasure principle: immersion, engagement, flow," in Proceedings of the 11th Conference on Hypertext and Hypermedia, pp. 153-160, 2000.

[11] B. Paras and J. Bizzocchi, "Game, motivation, and effective learning: an integrated model for educational game design," in Proceedings of the 2nd International Conference on Digital Games Research Association (DiGRA '05), Vancouver, Canada, June 2005.

[12] J. Reid, E. Geelhoed, R. Hull, K. Cater, and B. Clayton, "Parallel worlds: immersion in location-based experiences," in Extended Abstracts on Human Factors in Computing Systems (CHI '05), pp. 1733-1736, Portland, Ore, USA, 2005.

[13] D. Weibel, B. Wissmath, S. Habegger, Y. Steiner, and R. Groner, "Playing online games against computer- vs. humancontrolled opponents: effects on presence, flow, and enjoyment," Computers in Human Behavior, vol. 24, no. 5, pp. 22742291, 2008.

[14] M. Csikszentmihalyi, Flow: The Psychology of Optimal Experience, Harper Perennial, New York, NY, USA, 1990.

[15] M. Csikszentmihalyi, "The future of flow," in Optimal Experience: Psychological Studies of Flow in Consciousness, M. Csikszentmihalyi and I. S. Csikszentmihalyi, Eds., pp. 364383, Cambridge University Press, New York, NY, USA, 1988.

[16] M. Csikszentmihalyi, "The flow experience and its significance for human psychology," in Optimal Experience: Psychological Studies of Flow in Consciousness, M. Csikszentmihalyi and I. S. Csikszentmihalyi, Eds., pp. 15-35, Cambridge University Press, New York, NY, USA, 1988.

[17] M. Csikszentmihalyi, Finding Flow: The Psychology of Engagement with Everyday Life, Basic Books, New York, NY, USA, 1997.

[18] M. Blythe and M. Hassenzahl, "The semantics of fun: differentiating enjoyable experiences," in Funology: From Usability to Enjoyment, M. A. Blythe, K. Overbeeke, A. F. Monk, and P. C. Wright, Eds., pp. 91-100, Kluwer Academic Publishers, Dordrecht, The Netherlands, 2003.

[19] J. Murray, Hamlet on the Holodeck: The Future of Narrative in Cyberspace, The MIT Press, Cambridge, UK, 1997.

[20] E. Patrick, D. Cosgrove, A. Slavkovic, J. A. Rode, T. Verratti, and G. Chiselko, "Using a large projection screen as an alternative to head-mounted displays for virtual environments," in Proceedings of the SIGCHI Conference on Human Factors in Computing Systems, pp. 478-485, The Hague, The Netherlands, 2000. 
[21] D. Freeman, "Creating emotion in games: the craft and art of Emotioneering," Computers in Entertainment, vol. 2, no. 3, pp. 15-15, 2004.

[22] M. Lombard and T. Ditton, "At the heart of it all: the concept of presence," Journal of Computer-Mediated Communication, vol. 3, no. 2, 1997.

[23] A. Järvinen, S. Heliö, and F. Mäyrä, "Communication and community in digital entertainment services: prestudy," Tech. Rep. Hypermedia Laboratory Net Series 2, University of Tampere, Tampere, Fla, USA, 2002, http://tampub.uta.fi/tup/951-44-5432-4.pdf .

[24] R. Rettie, "An exploration of flow during internet use," Internet Research, vol. 11, no. 2, pp. 103-113, 2001.

[25] M. Csikszentmihalyi, Flow and the Psychology of Discovery and Invention, Harper Perennial, New York, NY, USA, 1997.

[26] T. P. Novak, D. L. Hoffman, and Y. F. Yung, "Measuring the customer experience in online environments: a structural modeling approach," Marketing Science, vol. 19, no. 1, pp. 22 42, 2000.

[27] M. Csikszentmihalyi, Beyond Boredom and Anxiety, JosseyBass, San Francisco, Calif, USA, 1975.

[28] Y. Y. Kim, S. Oh, and H. Lee, "What makes people experience flow? Social characteristics of online games," International Journal of Advanced Media and Communication, vol. 1, no. 1, pp. 76-91, 2005.

[29] M. Liljedahl, N. Papworth, and S. Lindberg, "Beowulfan audio mostly game," in Proceedings of the International Conference on Advances in Computer Entertainment Technology (ACE'07), vol. 203, pp. 200-203, 2007.

[30] T. Drewes, E. Mynatt, and M. Gandy, "Sleuth: an audio experience," in Proceedings of International Conference on Auditory Display (ICAD '00), Atlanta, Ga, USA, April 2000.

[31] J. C. Nunally, Psychometric Theory, McGraw-Hill, New York, NY, USA, 1978.

[32] C. Fornell and D. F. Larcker, "Evaluating structural equation models with unobservable variables and measurement error," Journal of Marketing Research, vol. 18, no. 1, pp. 39-50, 1981.

[33] L. S. Aiken and S. G. West, Multiple Regression: Testing and Interpreting Interactions, Sage, Newbury Park, Calif, USA, 1991.

[34] R. M. Baron and D. A. Kenny, "The moderator-mediator variable distinction in social psychological research. Conceptual, strategic, and statistical considerations," Journal of Personality and Social Psychology, vol. 51, no. 6, pp. 1173-1182, 1986. 

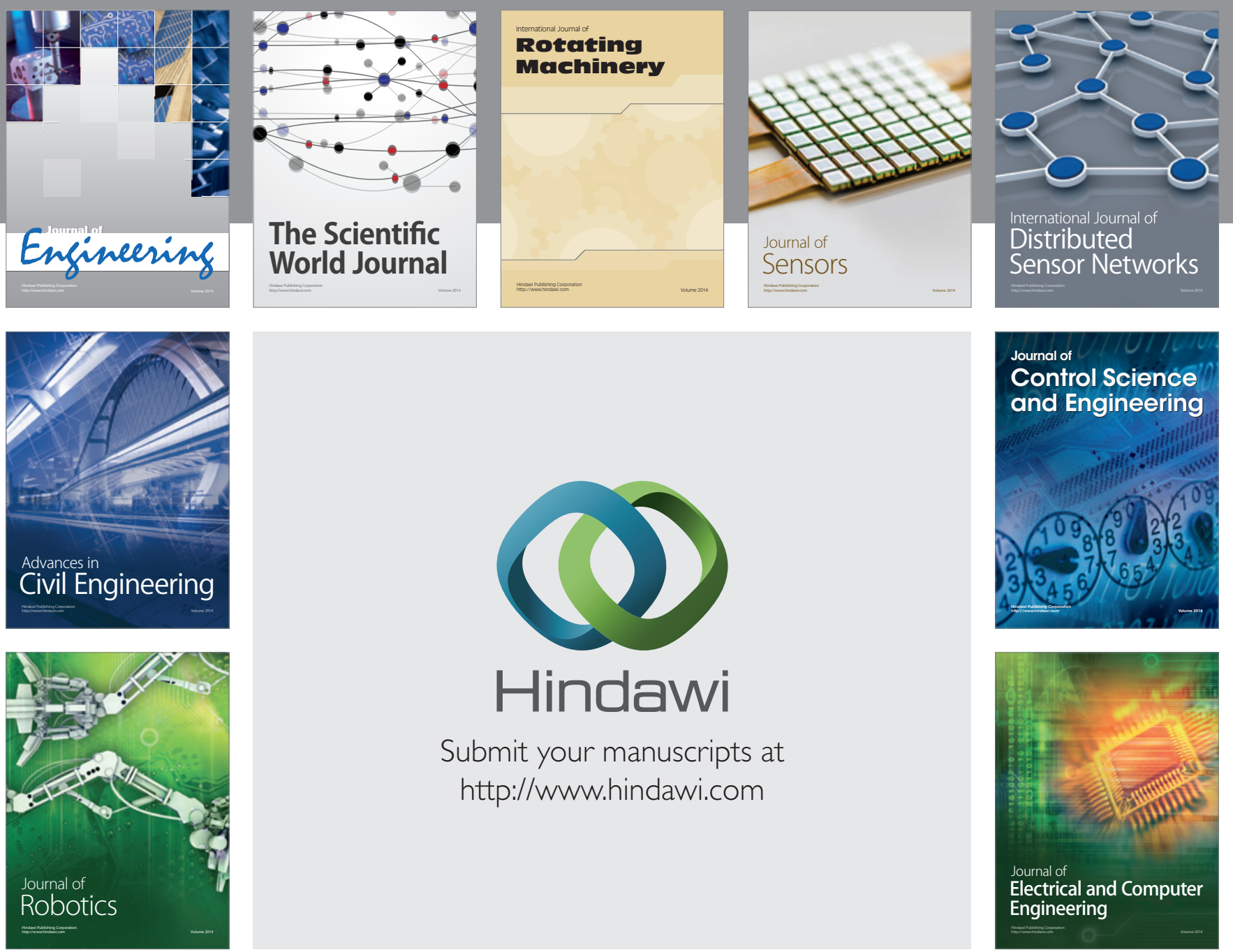

Submit your manuscripts at

http://www.hindawi.com
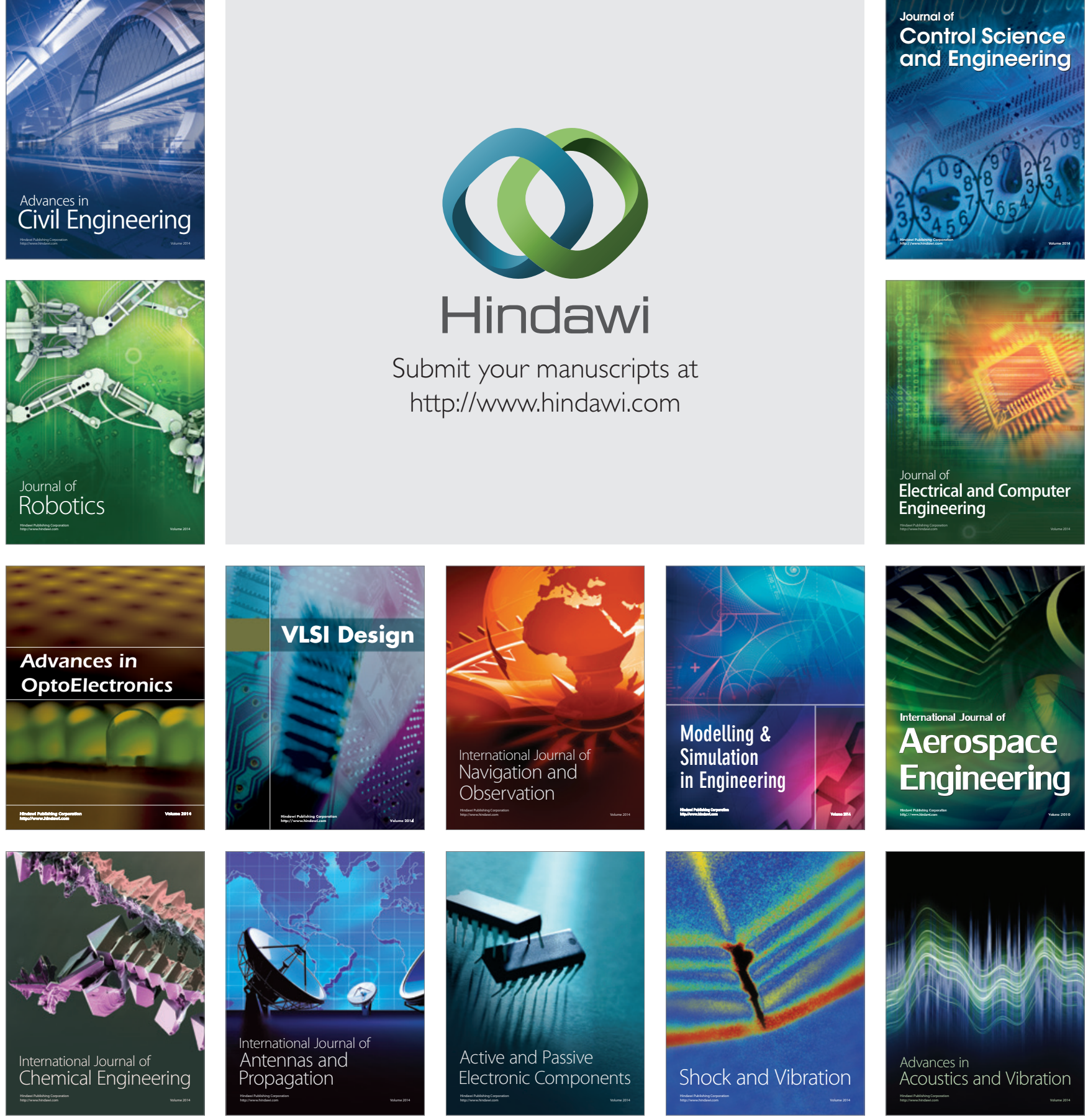